\title{
KEMAMPUAN MEMBAYAR IURAN BPJS BAGI MASYARAKAT PEKERJA SEKTOR INFORMAL (STUDI PADA TUKANG OJEK DAN BECAK/ BENTOR)
}

\author{
Abylity To Pay BPJS For Informal Sector Workers (Study In \\ Ojek And Becak/Bentor Drivers)
}

\author{
Nurbaeti ${ }^{1}$, Andi Surahman Batara ${ }^{2}$ \\ Fakultas Kesehatan Masyarakat Universitas Muslim Indonesia \\ Email : andisurahman.batara@umi.ac.id
}

\begin{abstract}
ABSTRAK
Penelitian ini bertujuan untuk mengetahui kesanggupan persentase penghasilan dalam membayar iuran BPJS bagi masyarakat pekerja sektor informal atau juga disebut pekerja bukan penerimah upah (PBPU) di kota Makassar. Target keluaran dalam penelitian ini yaitu mengetahui berapa besar kemampuan dalam membayar iuran setiap bulan bagi setiap orang jika mereka sebagai peserta BPJS Kesehatan maupun Ketenagakerjaan. Jenis penelitian adalah diskriptif dengan menggunakan data kuantitatif dan dijelaskan secara kualitatif. Populasi penelitian ini adalah masyarakat pekerja tukang Becak/Bentor/ ojek. Pengambilan sampel adalah simple random sampling yaitu teknik pengambilan sampel yang dilakukan secara acak (random). Sampel penelitian ini sebanyak 47 orang. Penelitian menemukan bahwa terdapat $74.5 \%$ pekerja tidak mempunyai kelebihan anggaran rumah tangga. Kemampuan membayar iuran BPJS sebesar 93.7\% orang yang sanggup mengeluarkan pembayaran BPJS 5\% dari jumlah penghasilan keluarga. Rata-rata penghasilan keluarga Rp. 1.500 .000 setipa bulan dengan anggota keluarga ratarata 6 orang.
\end{abstract}

Kata Kunci : BPJS, kemampuan membayar, pekerja sektor informal

\begin{abstract}
This tudy aims to determine the percentage of income capability in paying BPJS contributions for the informal sector workers' community or also commonly referred to as independent workers in the city of Makassar. The output target in this study is knowing how much ability to pay contributions every month for everyone if they are BPJS participants in Health and Employment. This type of research is descriptive using quantitative data and explained qualitatively. The results of the study will be analyzed statistically. The population of this study is the community of workers of Becak / Bentor, motorcycle taxi drivers. Sampling is simple random sampling, which is a random sampling technique. The sample of this study was 47 people. The study found that there were $74.5 \%$ of people who did not have excess household budget, so the ability to pay BPJS contributions. There were $93.7 \%$ of people who were able to pay BPJS payments 5\% of the total family income. Average family income of Rp. 1,500,000 every month with an average family member of 6 people.
\end{abstract}

Keywords : BPJS, ability to pay, informal sector workers

\footnotetext{
Sekretariat

Editorial: Kampus FKM UNISMUH PALU - Palu 94118, Sulawesi Tengah, Indonesia

Telp/HP: +6281245936241, Fax (0451) 425627

E-mail: jurnal.mppki@gmail.com

OJS: http://jurnal.unismuhpalu.ac.id/index.php/PJKM
}

\author{
Article History: \\ $\Rightarrow \quad$ Received 11 September 2018 \\ $\Rightarrow \quad$ Revised 08 Oktober 2018 \\ $\Rightarrow \quad$ Accepted 24 November 2018 \\ $\Rightarrow \quad$ Available online 31 Desember 2018
}




\section{PENDAHULUAN}

Masalah kesehatan masyarakat banyak dipengaruhi oleh faktor diluar kewenangan sektor kesehatan(Batara, Syafar, Palutturi, \& Stang, 2018). Sebagai contoh adalah pendapatan masyarakat, tempat kerja, jenis pekerjaan, dan sebagainya. Negara anggota World Health Organization (WHO) pada tahun 2005, telah berkomitmen membangun sistem pembiayaan kesehatan untuk menjamin akses pelayanan kesehatan dan memberi perlindungan terhadap risiko pendapatan. Hal tersebut merupakan upaya untuk mencapai tujuan cakupan kesehatan untuk seluruh penduduk. Banyak studi terdahulu yang menyatakan bahwa tantangan untuk mencapai universal health coverage adalah mencakup para pekerja sektor informal (Idris, Trisnantoro, \& Satriawan, 2015).

Di Indonesia sistem pembiayaan kesehatan mengalami reformasi sejak diterbitkannya Undang - Undang (UU) No 40 tahun 2004 tentang Sistem Jaminan Sosial Nasional (SJSN) dan UU No 24 tahun 2011 tentang Badan Penyelenggaraan Jaminan Sosial (BPJS) yang di setujui DPR RI bertepatan dengan peringatan Hari Sumpah Pemuda tanggal 28 Oktober 2011. Tahun 2012-2014 fokus pada persiapan beroperasinya BPJS Kesehatan. Fokus saat ini adalah perluasan kepesertaan menuju target pemerintah yaitu Universal Health Coverage (UHC) dicapai tahun 2019 (Anggraeni, Maidin, \& Arifah, 2016; Nopiyani, Indrayathi, Listyowati, Suarjana, \& Januraga, 2015; Thabrany, 2014; Yuliyanti \& Ratnawati, 2016). Hal ini berarti semua penduduk Indonesia harus terdaftar memiliki Jaminan Kesehatan Nasional di tahun 2019.

Jumlah penduduk Indonesia berdasarkan hasil SUPAS 2015 yaitu 255,18 juta jiwa (Profil Penduduk hasil SUPAS 2015, 2016). Berdasarkan hasil Sakernas tahun 2017 menunjukkan bahwa jumlah penduduk yang bekerja sebanyak 121,02 juta orang, sebanyak $60,93(50,35 \%)$ juta orang bekerja pada sektor informal (BPS, 2017). Data ini menunjukkan bahwa pekerja sektor informal masih mendominasi di Indonesia. Salah satu target perluasan kepersertaan dalam Peta Jalan menuju Jaminan Kesehatan Nasional adalah kepesertaan dikalangan pekerja mandiri bukan peneri- mah upah (sektor informal). Penyelenggaraan program jaminan sosial bagi pekerja sektor informal ini menjadi prioritas, karena tenaga kerja sektor informal ini mendominasi angkatan kerja di Indonesia (Adillah \& Anik, 2015).

The International Conference of Labour Statisticians (ICLS) yang ke-15 memberi defenisi sektor informal sebagai unit produksi dalam usaha rumah tangga yang dimiliki oleh rumah tangga (Indikator Pasar Tenaga Kerja Indonesia, Agustus 2017). Pekerja sektor informal adalah seorang yang bekerja secara mandiri (tanpa ikatan dengan pihak lain) dengan pendapatan tidak menentu setiap harinya. Selain itu tingkat pendapatan (upah) berada di bawah UMP (Kota Makassar Rp 2.000.000). Rata-rata pendapatan mereka adalah 1,5 juta/bulan(Tuwo, 2013). Pekerja sektor informal yang mendapatkan penghasilan dari usaha sendiri boleh mendaftarkan diri sebagai peserta BPJS dalam kurun waktu 2014-2019 (Thabrany, 2014).

Saat ini cakupan kepesertaan BPJS bagi pekerja bukan penerima upah (PBPU) sebesar 25.397.828 jiwa, peserta PBPU aktif 13.787.832 jiwa sedangkan tidak aktif 11.609.996 jiwa. Salah satu alasan peserta tidak aktif (dinonaktifkan sementara) karena tidak membayar iuran (menunggak) lebih dari 1 bulan sejak tanggal 10 setiap bulannya. Iuran bagi peserta Pekerja Bukan Penerima Upah dan Bukan Pekerja sebesar Rp 25.500,per orang per bulan dengan manfaat pelayanan di ruang perawatan Kelas III, sebesar Rp 51.000,- per orang per bulan dengan manfaat pelayanan di ruang perawatan Kelas II dan sebesar Rp 80.000,- per orang per bulan dengan manfaat pelayanan di ruang perawatan Kelas I (BPJS, 2017).

Tukang ojek dan tukang bentor/becak merupakan salah satu jenis pekerjaan sektor informal sebagai salah satu kategori PBPU. Aktifitas mereka masih banyak ditemui di Kota Makassar. Namun peneliti kesulitan menemukan jumlah populasinya. Peneliti tertarik untuk mengetahui kemampuan mereka membayar iuran BPJS.

\section{METODE PENELITIAN}

Penelitian ini merupakan penelitian kuantitatif dengan pendekatan survei deskriptif. Tidak ditemukan jumlah populasi 
yang pasti pada pekerja sektor informal tukang ojek/bentor/becak. Penelitian dilaksanakan di Kota Makassar. Sampel penelitian sebanyak 47 orang. Pengumpulan data dilakukan dengan kuesioner dan observasi terhadap situasi-situasi yang berhubungan dengan topik penelitian. Peneliti menggunakan pedoman observasi berupa lembaran daftar check. Pengolahan data dengan menggunakan SPSS.

\section{HASIL}

Hasil penelitian pada tabel 1 (lampiran) mengambarkan bahwa umur responden secara keseluruhan tergolong usia produktif dan tidak sekolah. Persentase terbesar umur 30 - 39 tahun yaitu $36.2 \%$ dan umur $40-49$ tahun sebesar $36.2 \%$.

Pada tabel 2 (lampiran) tingkat pendidikan responden berdasarkan hasil penelitian persentase terbesar adalah tidak sekolah atau tidak tamat SD sebesar 55.3\%.

Pada tabel 3 (lampiran) hasil penelitian menunjukkan bahwa lebih dari separuh jumlah responden mempunyai anak lebih dari 2 orang (59.5\% mempunyai jumlah anak 3 - 5 anak) sehingga rata-rata jumlah keluarga berkisar $5-7$ orang.

Pada tabel 4 (lampiran) biaya pendidikan kebanyakan masyarakat prasejahtera masih menjadi beban ekonomi keluarga, hal ini dapat dilihat pada hasil penelitian menunjukkan $57.4 \%$ terbebani dengan biaya sekolah anak.

Pada tabel 5 (lampiran) tingkat kesejahteraan ekonomi keluaga hampir separuh (46.8\%) mempunyai pendapatan per bulan kurang dari UMP yaitu Rp.2.000.000 dengan rata-rata kisaran Rp 1.000.000 sampai Rp 1.500 .000 .

Tabel 6 menunjukkan 74,5\% responden tidak memiliki kelebihan penghasilan dan $25,5 \%$ memiliki kelebihan penghasilan. Tabel 7 menunjukkan 12,8\% responden memliki pendapatan $<1$ juta perbulan, sebanyak $66,0 \%$ responden memiliki $1-1,9$ juta perbulan, sebanyak $17 \%$ memiliki pendapatan 2 - 2,9 juta, sebanyak $2,1 \%$ responden memiliki pendapatan $>4$ juta. Tabel 8 menujukkan $89,4 \%$ setuju dan $4,3 \%$ sangat setuju membayar iuran $5 \%$ dari pendapatan perbulan.

\section{PEMBAHASAN}

Hak setiap warga negara untuk memperoleh jaminan sosial (social security). Salah satu bentuk jaminan sosial itu adalah jaminan kesehatan. Akses terhadap jaminan sosial merupakan hak dasar bagi setiap warga negara di dunia ini. Jaminan kesehatan merupakan program pemerintah dan rakyat yang bertujuan memberikan kepastian jaminan kesehatan bagi seluruh rakyat Indonesia agar dapat hidup sehat, produktif dan sejahtera (Irawan, Usman, Berliana, \& Wicaksono, 2016). Di Indonesia jaminan kesehatan "diurus" oleh BPJS. Salah satu bentuk kepesertaan BPJS adalah peserta pekerja bukan penerima upah (PBPU). Mereka harus membayar iuran setiap bulannya dengan besaran tertentu sesuai dengan kelas perawatan yang diinginkan. Namun tidak bisa dipungkiri bahwa masih banyak rakyat yang kesulitan melakukan pembayaran iuran setiap bulannya.

Kemampuan membayar jaminan kesehatan sangat tergantung pada tingkat pendapatan (Djahini-Afawoubo \& Atake, 2018). Sama halnya pada pekerja sektor informal (tukang ojek), kemampuan mereka membayar iuran BPJS (Ability to Pay) sangat dipengaruhi faktor penghasilan dan jumlah tanggungan keluarga dalam rumah tangga. Akses pelayanan kesehatan tidaklah mudah bagi mereka yang berpendapatan rendah (miskin) dan pekerja sektor informal (Sarkar, 2007). Penelitian ini menunjukkan bahwa para pekerja sektor informal menginginkan pembayaran iuran setiap bulan dibebankan kepada salah satu anggota keluarga saja yang menanggung untuk semua anggota keluarga. Hal ini sangatlah beralasan, karena pekerja sektor informal tidak mempunyai kelebihan pendapatan. Pendapatan mereka hanya cukup untuk biaya hidup (makan, sewa rumah, dll).

Banyak bukti yang menunjukkan bahwa tingkat sosial ekonomi seperti pendapatan dan pendidikan berkaitan dengan askes pada layanan kesehatan. Keadilan akses layanan kesehatan (health equity) dianggap sebagai komponen kunci pencapaian Universal Health Coverage yang juga bagian dari upaya mewujudkan pembangunan yang berkelanjutan atau Sustainable Development Goals (SDGs) (Huda, Hayes, Arifeen, \& Dibley, 2017). 
Penelitian di Amerika membuktikan bahwa pendapatan keluarga dan kepemilikan asuransi (jaminan kesehatan) memiliki hubungan yang bermakna terhadap akses layanan kesehatan (Fitzpatrick, Powe, Cooper, Ives, \& Robbins, 2004). Kemiskinan juga terbukti menjadi faktor penghambat akses terhadap layananan kesehatan (Jacobs, Ir, Bigdeli, Annear, \& Damme, 2012). Penelitian di India membuktikan bahwa kepemilikan jaminan kesehatan dapat meningkatkan akses layanan kesehatan (Devadasan et al., 2010). Di Indonesia, kepemilikan kartu BPJS ini merupakan salah satu upaya mewujudkan keadilan akses layanan kesehatan. Harapannya, tidak ada lagi warga negara yang tidak memanfaatkan layanan kesehatan karena alasan tidak memiliki biaya.

\section{KESIMPULAN DAN SARAN}

Perkerja sektor informal dalam hal ini tukang ojek memiliki penghasilan rata-rata Rp. 1.500.000 / bulan dengan jumlah anggota keluarga dalam rumah tangga $5-7$ orang. Penelitian ini menemukan $74.5 \%$ keluarga tidak mempunyai kelebihan anggaran rumah tangga bahkan mereka mengatakan tidak cukup memenuhi kebutuhan dasar rumah tangganya. Oleh karena itu mereka masih mengharapkan bantuan iuran BPJS. Kemampuan membayar iuran bagi yang belum mendapat bantuan terdapat 93,7\% mempunyai kemampuan 5\% dari penghasilan untuk pembayaran BPJS dengan anggota keluarga rata-rata 6 orang dalam satu keluarga. Disarankan penentuan besar iuran BPJS bagi pekerja sektor informal harus mempertimbangkan kemampuan mereka membayar.

\section{DAFTAR PUSTAKA}

Adillah, S. U., \& Anik, S. (2015). Kebijakan Jaminan Sosial Tenaga Kerja Sektor Informal Berbasis Keadilan Sosial Untuk Meningkatkan Kesejahteraan. Yustisia, 4(03), 558 - 580.

Anggraeni, R., Maidin, A., \& Arifah, N. (2016). Gambaran Kepuasan Petugas Kesehatan dan Peserta Jaminan Kesehatan Nasional di Provinsi Sulawesi Selatan, Sulawesi Tenggara dan Sulawesi Barat Tahun 2014. Jurna Kebijakan Kesehatan Indonesia, 05.
Batara, A. S., Syafar, M., Palutturi, S., \& Stang. (2018). Pentingnya Kolaborasi Stakeholder Dalam Mewujudkan Terminal Sehat di Sulawesi Selatan. Media Publikasi Promosi Kesehatan Indonesia, 1(1), 17 - 20.

BPJS. (2017). Laporan Pengelolaan Program dan Laporan Keuangan Jaminan Sosial Kesehatan Tahun 2017.

BPS. (2017). Indikator Pasar Tenaga Kerja Indonesia, Agustus 2017.

Devadasan, N., Criel, B., Damme, W. V., Manoharan, S., Sarma, P. S., \& Stuyft, P. V. d. (2010). Community health insurance in Gudalur, India, increases access to hospital care. Health Policy and Planning, 25, 145 - 154.

Djahini-Afawoubo, D. M., \& Atake, E.-H. (2018). Extension of mandatory health insurance to informal sector workers in Togo. BMC Health Economic Reviews.

Fitzpatrick, A. L., Powe, N. R., Cooper, L. S., Ives, D. G., \& Robbins, J. A. (2004). Barriers to Health Care Access Among the Elderly and Who Perceives Them. American Journal of Public Health, 94(10), 1788 - 1794.

Huda, T. M., Hayes, A., Arifeen, S. E., \& Dibley, M. J. (2017). Social determinants of inequalities in child undernutrition in Bangladesh: A decomposition analysis. Maternal \& Child Nutrition.

Idris, H., Trisnantoro, L., \& Satriawan, E. (2015). Perluasan Kepesertaan Jaminan Kesehatan Bagi Pekerja Sektor Informal (Studi Evaluasi Pra dan Pasca Jaminan Kesehatan Nasional). Jurnal Kebijakan Kesehatan Indonesia, 04(4).

Indikator Pasar Tenaga Kerja Indonesia, Agustus 2017. Badan Pusat Statistik.

Irawan, P. B., Usman, H., Berliana, S. M., \& Wicaksono, F. (2016). Official Statistics Sosial - Kependudukan Dasar. Bogor: iN MEDIA.

Jacobs, B., Ir, P., Bigdeli, M., Annear, P. L., \& Damme, W. V. (2012). Addressing access barriers to health services: an analytical framework for selecting appropriate interventions in low-income Asian countries. Health Policy and Planning, 27, 288 - 300.

Nopiyani, N. M. S., Indrayathi, P. A., Listyowati, R., Suarjana, I. K., \& Januraga, P. P. (2015). Akses Jaminan Kesehatan Na- 
sional pada Pekerja Seks Perempuan. Jurnal Kesehatan Masyarakat Nasional, 9(4).

Profil Penduduk hasil SUPAS 2015. (2016). Badan Pusat Statistik.

Sarkar, S. (2007). Health Insurance for the Poor in Informal Sector. Indus Journal of Management \& Social Sciences, 1(2).

Thabrany, H. (2014). Jaminan Kesehatan Nasional. Jakarta: Rajawali Pers.

Tuwo, L. D. (2013). Universal Health Coverage Bagi Sektor Informal. http:// www.jamsosindonesia.com/kjs/files/ flash/a/Dari Wamen PPN-Waka Bappenas - High level Informal Sector Forum - Yogyakarta 30 Sept 2013-1.pdf.

Yuliyanti, S., \& Ratnawati. (2016). Gambaran Pelaksanaan Pelayanan BPJS Kesehatan Di Fasilitas Kesehatan Tingkat Pertama di Kota Semarang. Jurnal Kebijakan Kesehatan Indonesia, 05. 


\section{LAMPIRAN}

Tabel 1. Distribusi Responden Berdasarkan Umur

\begin{tabular}{lrr}
\hline & Frekuensi & Persen \\
\hline$<30$ tahun & 9 & 19,1 \\
$30-39$ tahun & 17 & 36,2 \\
$40-49$ tahun & 17 & 36,2 \\
$>=50$ tahun & 4 & 8,5 \\
\cline { 2 - 3 } Total & 47 & 100,0
\end{tabular}

Sumber: Data Primer, 2018

Tabel 2. Distribusi Responden Berdasarkan Tingkat Pendidikan

\begin{tabular}{lrr}
\hline & Frekuensi & \multicolumn{2}{c}{ Persen } \\
\hline Tidak Sekolah & 26 & 55,3 \\
SD & 13 & 27,7 \\
SLP & 8 & 17,0 \\
\cline { 2 - 3 } & & \\
\hline Total & 47 & 100,0
\end{tabular}

Sumber: Data Primer, 2018

Tabel 3. Distribusi Responden BerdasarkanJumlah Anak

\begin{tabular}{lccc}
\hline & Frekuensi & \multicolumn{2}{c}{ Persen } \\
\hline$<=2$ orang & 19 & 40,4 \\
$3-4$ orang & 23 & 48,9 \\
$>=5$ orang & 5 & 10,6 \\
\cline { 2 - 3 } & Total & 47 & 100,0
\end{tabular}

Sumber: Data Primer, 2018 
Tabel 4. Distribusi Responden Berdasarkan Terbeban Biaya Sekolah

\begin{tabular}{llcc} 
& Frekuensi & Persen \\
\hline Ya & 27 & 57,4 \\
Tidak & 20 & 42,6 \\
\cline { 2 - 3 } & Total & 47 & 100,0 \\
\hline
\end{tabular}

Sumber: Data Primer, 2018

Tabel 5. Distribusi Ressponden Berdasarkan Terpenuhi Kebutuhan Rumah Tangga

\begin{tabular}{lrr} 
& Frekuensi & \multicolumn{2}{c}{ Persen } \\
\hline Cukup & 25 & 53,2 \\
Tidak Cukup & 22 & 46,8 \\
& & \\
\cline { 2 - 4 } & & \\
\hline
\end{tabular}

Sumber: Data Primer, 2018

Tabel 6. Distribusi Responden Berdasarkan Kelebihan Pendapatan

\begin{tabular}{llrr}
\hline & Frekuensi & \multicolumn{2}{c}{ Persen } \\
\hline Ada & 12 & 25,5 \\
Tidak ada & 35 & 74,5 \\
\cline { 2 - 3 } & Total & 47 & 100,0
\end{tabular}

Sumber: Data Primer, 2018 
Tabel 7. Distribusi Responden Berdasarkan Jumlah Pendapatan Per Bulan

\begin{tabular}{lcr}
\hline & Frekuensi & \multicolumn{2}{c}{ Persen } \\
\hline$<1,0$ juta & 6 & 12,8 \\
$1,0-1,9$ juta & 31 & 66,0 \\
$2,0-2,9$ juta & 8 & 17,0 \\
$3,0-3,9$ juta & 1 & 2,1 \\
$>=4,0$ juta & 1 & 2,1 \\
\hline Total & 47 & 100,0 \\
\hline
\end{tabular}

Sumber: Data Primer, 2018

Tabel 6. Distribusi Responden Kemauan Membayar Iuran BPJS 5\% dari Jumlah Pendapatan Per Bulan

\begin{tabular}{lrrr}
\hline & Frekuensi & \multicolumn{2}{c}{ Persen } \\
\hline Sangat setuju & 2 & 4,3 \\
Setuju & 42 & 89,4 \\
\cline { 2 - 3 } & & & \\
& Tidak setuju & 3 & 6,4 \\
\cline { 2 - 3 } & Total & 47 & 100,0 \\
\hline
\end{tabular}

Sumber: Data Primer, 2018 